Emad Khazraee, Kristene Unsworth:

\title{
Social media: The new opiate of the masses?
}

\begin{abstract}
:
This study argues that the relationship between new information and communication technologies (ICT) and social movements should be done from a socio-technical perspective. In the present study, we broaden this perspective and use Actor-Network Theory (ANT) to better understand the relationship between social media (as a new ICT) and social movements. From the perspective of ANT, one cannot define unidirectional causal relationships between the social and the technical. New technical developments create opportunities to change the social order and in the meantime technologies are transformed and are adapted differently by humans. Preliminary findings examining the use of Facebook among Iranians, applying the aforementioned relational sociology perspective based on ANT, suggest that the role new ICTs play in social movements and social change is not linear and constant through time. The impact of new ICTs might be different considering different stages in a social movement timeline. In fact, there may be a stage where ICTs actually function as a sort of pressurerelease value, allowing individuals to remain content within the status quo rather than choosing to pursue more radical goals. We propose the utilization of the two concepts of "durability" and "mobility", from ANT literature, to better understand the potential of online social networking technologies for social change. We suggest three different time stages as short (emergence of movements), mid (development or decline of movements), and late stage (the movement's continuation, survival or disappearance through time) to be considered in the study of relationship between social media and social change.
\end{abstract}

\section{Agenda:}

Introduction

Background

Empirical Study

Sampling Strategy and Data collection

Discussion .

Lack of Dialogue

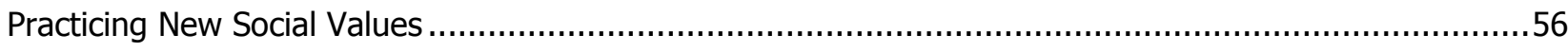

Transitory Collective Identities vs. Durable Collective Identities ...................................................56

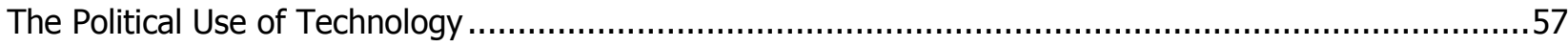

Conclusion 


\section{Authors:}

Emad Khazraee:

- 3141 Chestnut Street, iSchool at Drexel University, Philadelphia, PA 19104, USA

- $: \mathbf{m}+1$ - 215 - $8959423, \square$ emad@drexel.edu

Kristene Unsworth:

- 3141 Chestnut Street, iSchool at Drexel University, Philadelphia, PA 19104, USA

- 疋 + 1 - 215 - 895 6016, $ه$ kristene.unsworth@drexel.edu

- Relevant publications:

- Unsworth, K. (under review). Citizen participation in the global surveillance society: An obligation to inform? Surveillance \& Society. 


\section{Introduction}

Some studies have scrutinized the relationship between new Information and Communication Technologies (ICT)s and social movements ${ }^{1}$. We argue that in order to gain a more complete understanding of the issues such studies should be done from a socio-technical perspective. Analyzing the role of social media from either reductionist pole (technological determinism or human reductionism) does not provide a precise picture of the relationships between social media, social change and social movements. From a socio-technical perspective, unidirectional causal relationships between the social and the technical are not defined nor is it possible to consider them as separate entities ${ }^{2}$. Therefore, one cannot argue that the recent social movements are direct results of technological developments (emergence of social media) rather that they are the result of a complex network of social and technical entities ${ }^{3}$. It is important to consider that social and technical phenomena constantly shape and form each other. New technical developments create opportunities to change the social order and in the meantime technologies are transformed and are adapted differently by humans. This relationship is not merely an interactional relationship but rather it is an entanglement situation ${ }^{4}$. The present study reports on preliminary findings examining the use of Facebook among Iranians, applying the aforementioned relational sociology perspective based on Actor-Network Theory (ANT).

Following ANT, we consider social order as the effect of a translation process of a complex heterogeneous socio-technical network (including both humans and non-humans). We propose the utilization of the two concepts of "durability" and "mobility" developed by ANT writers to better understand the potential of online social networking technologies for social change. Based on early findings of our study we suggest that there is a temporal aspect to the degree of effect based on social media use. We propose three different stages as early (emergence of movements), mid (development or decline of movements), and late stage (the movement's continuation, survival or disappearance through time) to be considered in the study of relationship between social media and social change. In each of the stages there is the opportunity for multiple forces to interact. The fact that social media is being used by individuals engaged in certain social movements does not preclude that the government or those in power aren't using the same technologies to maintain the status quo. Similar to the manner in which Marx invoked religion as an opiate for the people, or as a means to placate the masses by allowing them some sense of freewill, social media technologies appear to be used in our study as a pressure-release valve. The government is certainly aware of the existence of Facebook pages that transgress religious law. Social media or Facebook in particular, appears to be serving a similar purpose to the public's gravitation to religion as discussed by Marx ${ }^{5}$.

\section{Background}

Attempts have been made to study the relationship between ICTs and new media ${ }^{6}$. These studies have utilized social movement theory to understand the role new ICTs play in social movements' emergence, development and outcome. An effort to integrate multiple perspectives in the field of social movements is presented in the Comparative Perspectives on Social Movements by McAdam, McCarthy and Zald ${ }^{7}$. The framework defines three

\footnotetext{
${ }^{1}$ van de Donk et al., Cyberprotest, Garrett, "Protest in an Information Society"; Meier, "Do 'liberation Technologies' Change the Balance of Power Between Repressive States and Civil Society?".

${ }^{2}$ Latour, Reassembling the Social, Law, "Notes on the Theory of the Actor Network: Ordering, Strategy and Heterogeneity."

${ }^{3}$ Law, "Notes on the Theory of the Actor Network: Ordering, Strategy and Heterogeneity."

${ }^{4}$ Orlikowski, "Sociomaterial Practices."

${ }^{5}$ Marx, Critique of Hegel's "Philosophy Of Right."

${ }^{6}$ van de Donk et al., Cyberprotest, Garrett, "Protest in an Information Society"; Meier, "Do 'liberation Technologies' Change the Balance of Power Between Repressive States and Civil Society?".

${ }^{7}$ McAdam, McCarthy, and Zald, Comparative Perspectives on Social Movements.
} 
aspects for social movements as: mobilizing structures (mechanisms that facilitate collective action), opportunity structures (societal conditions in which social movements develop), and framing processes (collective strategic attempts to construct shared meanings and understandings that help to legitimize and to propagate movement narratives and form collective identities) ${ }^{8}$.

Although technologies and technological artifacts form an important part of social systems, they should not be considered merely as tools and means that are directed by social interests, but as integral parts of the system interwoven with the social fabric ${ }^{9}$. In the present study, we broaden this perspective and use ANT to better understand the relationship between social media (as a new ICT) and social movements.

From the perspective of ANT, social order is an achievement and the result of a translation process that transforms a set of interests and actors (human and non-human) into a complex heterogeneous network ${ }^{10}$. Therefore, any social movement can be seen as the formation of such actor-networks that challenges the existing social order. Callon ${ }^{11}$ describes four steps of translation process as: problematization (the process to become indispensable), interessement ${ }^{12}$ (the process whereby the associations between actors who support a network are locked into the place and their identities are stabilized in the network), enrollment (the process to define and coordinate the roles), and mobilization (mobilization of allies to achieve the goal). We suggest considering these four steps to better understand the role of new ICTs in social movements.

The success of actor-networks depends on multiple factors. ANT writers argue that networks consist of different materials (i.e. technological artifacts) and "some materials are more durable than others and so maintain their relational patterns for longer ... [t] hus a good ordering strategy is to embody a set of relations in durable materials"13. Therefore, more resistant networks consist of and are performed by durable materials. This concept can be used to study to what extent we can consider social media as a durable material to form an actornetwork in favor of social change.

The concept of durability refers to the way the materiality or technologies of an Actor-Network can maintain their ordering effects in the network through time and resist against the other competing networks and strategies. Whereas mobility is concerned with the spread of ordering effects of networks through space, in particular, how networks can extend their effects to spatial and geographically distant areas ${ }^{14}$. Evidence suggests that social media technologies are very mobile and effective tools to use to coordinate critical masses of people to engage in events ${ }^{15}$. Garret and Meier ${ }^{16}$ discuss in detail how new ICTs contribute to the mobilization structures in social movements. Social media enables citizens to instantaneously broadcast their words to geographically distant regions. This mobility has the potential to contribute to the effect of the messages.. For example, social media can be used to mobilize public opinion promptly through widespread diffusion of the news and provide evidence about a social movement. However, it is necessary to ask whether new ICTs in general and social media in particular are durable materials for social change. In other words, whether they can overcome resistance from existing power, or if networks formed around social media technologies will become impoverished under constant repression. One should note that it is still very early for social media

\footnotetext{
${ }^{8}$ Snow et al., "Frame Alignment Processes, Micromobilization, and Movement Participation"; Benford and Snow, "Framing Processes and Social Movements."

${ }^{9}$ Law, "On the Methods of Long-distance Control: Vessels, Navigation and the Portuguese Route to India."

${ }^{10}$ Law, "Notes on the Theory of the Actor Network: Ordering, Strategy and Heterogeneity."

${ }^{11}$ Callon, "Some Elements of a Sociology of Translation: Domestication of the Scallops and the Fishermen of St Brieuc Bay."

${ }^{12}$ We used the same terms that Callon used for conceptualizing translation process (e.g. interestment).

${ }^{13}$ Law, "Notes on the Theory of the Actor Network: Ordering, Strategy and Heterogeneity," 6.

${ }^{14}$ Ibid.

${ }_{15}$ Myers, "Communication Technology and Social Movements"; Bennett and Segerberg, "Digital Media and the Personalization of Collective Action"; Bennett, "The Personalization of Politics Political Identity, Social Media, and Changing Patterns of Participation."
}

${ }^{16}$ Garrett, "Protest in an Information Society"; Meier, "Do 'liberation Technologies' Change the Balance of Power Between Repressive States and Civil Society?". 
technologies to be assessed in this regard. In the last decade, we have seen the rise and fall of many different social networking technologies (e.g. Orkut, Yahoo 360 and MySpace to some extent). In addition, it is important to study whether social networking sites can keep the public engaged in discussions about social change or if their impact on public opinion mobilization will be diminished shortly after the start of uprisings and the emergence of a social movements; therefore, before considering any strong claim about the role of social media in social change, it behooves us to consider the durability of such technologies.

\section{Empirical Study}

This exploratory study was performed to better understand the adaptation of Facebook in Iran as representative of a cultural setting different from that of Facebook's design and creation. The study was done in two phases. In the first, qualitative interviews were utilized to understand how Iranians use Facebook. In the second, content analysis was done on the status updates and posts of eight users in Facebook over a 20 days period to understand the major topics and patterns of use among a sample of users.

\section{Sampling Strategy and Data collection}

Collecting data about online social networking practices on Facebook is not easy for two reasons: First, an important aspect of such social practice is considered private and cannot be observed publicly. Second, companies such as Facebook are reluctant to share data. As a result, in this study we followed a stratified quota sampling strategy which is a common practice in qualitative research especially when looking at a small number of subjects ${ }^{17}$.

A recent major study on General Media Use (GMU) in Iran ${ }^{18}$ portrays the landscape of media consumption in the country. The statistics and demographics derived from this data set were used to stratify the sample for the present study. Our aim was to include participants who reflected a similar socio-demographic population to the online social network users identified in the GMU study (Table 1). This stratification strategy was applied to both phases of the study.

In the first phase, eight users were interviewed to learn how Iranians use Facebook. Interviewees were selected from a list compiled through a snowball sampling strategy. The interviews followed a semi-structured model (one face-to-face and seven phone interviews). Each interview lasted for about an hour. Following the GMU survey, we picked our participants from major urban areas (five major cities) in Iran and one participant outside Iran, who has recently left the country, as a comparative case which can reveal the differences between inside and outside Iran. The sample consists of four female and four male participants. Regarding educational achievement three participants held a high school degree, four held an undergraduate degree and one with a graduate degree. The interviews were transcribed and imported into Atlas.ti software for qualitative data analysis.

In the second phase of the study, a research collaborator who had 1560 Facebook friends stratified her friend list based on our sampling strategy and then picked random subjects from each group (in total 8 subjects). In this phase our sample consisted of four female and four male subjects. Three subjects held a high school degree, four an undergraduate degree and one with graduate degree. The research collaborator was asked to monitor the subjects' status updates and posts for a period of 20 days. Then, any private personal information was removed and the data set was anonymized by the collaborator. The purpose of this phase was to better understand the patterns and frequencies of Facebook use among subjects and to recognize the type and subject of contents mostly shared by the users ( $\mathrm{N}=247$ for status updates and posts).

\footnotetext{
${ }^{17}$ Lindlof and Taylor, Qualitative Communication Research Methods, Patton, Qualitative Research and Evaluation Methods.

${ }_{18}$ Wojcieszak, Smith, and Enayat, Finding a Way: How Iranians Reach for News and Information. The Iran Media Program's 2011-2012 Report on Media Consumption in Iran.
} 
Utilizing ANT as a conceptual lens, in both phases of the study we looked to understand: 1) how the participants shape and are shaped by the use of Facebook. And 2) whether Facebook can serve as a durable platform for instigating social change.

Table 1: Statistics of social networks users in Iran from General Media Use (GMU) survey ${ }^{19}$

Total percent of social networks users among internet
users

Percent of Social network users by age group

Between 18-40 yrs.

$92 \%$

Between 18-30 yrs.

$72 \%$

Between 18-25 yrs.

$54 \%$

\section{Percent of Social network users by education level}

$\begin{array}{lr}\text { Graduate degree } & 9 \% \\ \text { Undergraduate degree } & 51 \% \\ & 35 \%\end{array}$

Below high school

$4 \%$

(Survey Period: 12 January - 29 February 2012; N=1022)

\section{Discussion}

Participants in this study spend a considerable amount of time on Facebook despite the existence of obstacles in Iran which limit Facebook use such as low speed Internet connections and filtering. One reason, emphasized by all participants, is that Facebook creates an extension to their existing social life. In this arena, they can participate in a different form of social life that is free from the official restrictions imposed by the government or the dominant discourse in society; thereby effectively, forming a separate social sphere. Moreover, this extension to their social life allows them a space where they can address some of the restrictions on social freedom regardless of their geographical location, gender or other barriers enforced through social norms. In a sense, this makes it possible to maintain two parallel realities which represent two discourses. One follows the official discourse in society encouraged by government, and the other follows the unofficial discourse practiced by many people privately. For example, in Iran, officially it is mandatory for females to practice $\mathrm{Hijab}^{20}$, whereas in many families and certain parts of society it is not an enforced value; therefore, in more private spaces females may not follow this rule. This is what we consider unofficial discourse. Online social networking environments such as Facebook create more possibilities to practice the unofficial discourse.

Among the participants of the interviews two groups can be distinguished, those with minimal interest in the use of the Facebook environment for political causes and those who consider Facebook as an environment that may contribute to social change. The latter group mentioned some frustration related to their initial assumption about the use of Facebook as a means to social change. They mentioned that political issues were a dominant trend on Facebook for just a short period of time after the 2009 uprisings in Iran and now mostly issues of everyday life dominate the Facebook environment.

\footnotetext{
${ }^{19}$ Ibid.

${ }^{20}$ The Oxford English Dictionary defines Hijab as: "The practice observed by some Muslim women of wearing concealing clothing (esp. Headgear)."
} 
This issue was confirmed by the findings of the GMU survey ${ }^{21}$ which indicate that political topics are not the top agenda item of discussions on social media for tech savvy Iranian youth, but stand at the fourth place behind personal topics, new technologies and work-related affairs. Results of the second phase of our study also suggested similar findings. Just one user among the eight was primarily posting content with political subjects, which made up for half of political posts in the entire sample. The share of posts with topics related to social change was $27 \%$ of total posts $(\mathrm{N}=427)$ while the share of posts about daily life and personal impressions was $62 \%$. These findings, to some extent, confirm the concern of those participants of the study who support social change; that social media may have a counter-effect in the mid-stage of social movement development. As mentioned above, social networks can provide an extension to the reality of physical social life. This extension, in some cases, satisfies some of the needs that cannot be fulfilled in the physical world. This in turn might work as a safety valve which actually undermines the potential for social activism in two ways.

First, presence in online social networks replaces the physical world and the actions that may occur to initiate social change in the repressive environments. For example, activists may assume that their activities in the online space suffice, thus they would not participate in contentious physical world activities. This has been considered as an impediment among those participants of the study who formerly were expecting Facebook as a means to support social change and were actively attempting to use it for such a purpose. Moreover, the decrease in the amount of activism in the physical world might decrease the durability of the networks of social change forces.

Second, in many societies, one of the causes that motivate people to object to the status quo is the lack of social space and interaction, especially among people in younger generations. Facebook provides such spaces for Iranian youth to represent themselves in the way they like (e.g. a personal image of a female not wearing the mandatory hijab) or socialize more cordially and freely with friends, especially of the opposite sex. This function of online social networks as an extension of physical social life provides a level of satisfaction that may ultimately vent some of the dissatisfaction felt by the youth, or as first referenced by Marx in relation to religion, as an opiate that relieves their anger to protest in the material social sphere. Social media, rather than being a tool used by individuals to express their independence, has the danger of being something that can be coopted by the state. From the perspective of the two parallel realities mentioned above, it explains that unofficial reality can be represented in the online social networks to reduce the conflict between the two realities. In this light the technology may in fact reduce the will to social change.

\section{Lack of Dialogue}

One of the complaints of the participants, who were looking to use Facebook as a platform in favor of social change, was that these technologies do not support dialogue. Only short interactions can be formed on Facebook which are only good for specific ends. In some cases, activists need a space for dialogue to negotiate strategies and achieve consensus. They argue that Facebook better serves mundane causes than social change. One may conclude that this means that technologies such as Facebook cannot form durable networks that support social change effectively.

Considering a social movement process as a translation process from an ANT perspective, social movements require an enrollment process in which different actors negotiate their roles and actions. This means if participants intend to go further than ad-hoc arrangements in a short period of time the enrollment process will require a negotiation and dialogue environment. Particularly, actors should be able to align their interests and coordinate their roles. One can argue the lack of proper negotiation capabilities will reduce the durability of social networking technologies for the mid-stage and the late-stage of a social movement.

\footnotetext{
${ }^{21}$ Wojcieszak, Smith, and Enayat, Finding a Way: How Iranians Reach for News and Information. The Iran Media Program's 2011-2012 Report on Media Consumption in Iran, 33.
} 


\section{Practicing New Social Values}

The findings of the study suggest that the younger generation, especially those from more conservative families, start adapting and practicing new social values in the extended reality environment. These values conform more closely with the unofficial discourse, or their interactions on Facebook. This may have the potential to lead to internalizing these values in the long-term.

Challenging power requires cognitive liberation ${ }^{22}$. Cognitive liberation in one sense requires questioning existing value systems and the dominant discourse as well as overcoming fear. Our actions are rooted in our value systems ${ }^{23}$; therefore, internalizing more relaxed social values may contribute to the social change in favor of the unofficial discourse in the long-term in Iran. It is important to note that unofficial discourse is not merely a cognitive phenomenon but embodied and practiced. Considering the social movement framework ${ }^{24}$, mainstream discussions on routine life issues might not directly contribute to the "cognitive liberation" process and to questioning the existing socio-political situation in the early-stage of a social movement, however, practicing new norms and values might help the framing processes in the long-term to legitimize unofficial discourse. Facebook provides a platform for such unofficial discourse to be practiced and embodied. This suggests that in studying the role of new ICTs in social movement we have to consider different stages. New ICTs might have very different functions in the early-stage, in the mid-stage and in the late-stage of a social movement.

All of the participants in the study use circumvention tools to access the Facebook (which is considered as an illegal action in Iran). Also, all participants mentioned that they have personally heard stories from friends and acquaintances about the security threats that they have faced because of the use of Facebook. In spite of all of these threats they are still using Facebook. Gamson ${ }^{25}$ argues that even when the legitimacy of oppressive regimes is questioned people should still overcome their fear to form a social movement. Using illegal circumvention tools, banned media resources, and online social networking environments in the mid-stage of a social movement may release some steam, but in the long-term may help overcome the fear of repressive forces. Understanding this aspect requires longitudinal studies on a larger scale.

\section{Transitory Collective Identities vs. Durable Collective Identities}

"Mediating between opportunity, organization, and action are shared meaning and definitions that people bring to their situation"26. Political process models emphasize that shared and socially constructed ideas and collective identities are necessary for collective action. New ICTs have the ability to accelerate and geographically broaden the diffusion of information ${ }^{27}$. In the case of Iranian Facebook users, we have witnessed cases that some events initiated formation of transitory collective identities (e.g. the case of Majid Tavakoli's arrest ${ }^{28}$ ), but none of the cases lasted for a long time. One might argue that social online networking technologies can contribute to quickly spreading the word to a vast geographical area (very mobile technologies) but their effect lasts only for a short time (not durable technologies). Thus, one can suggest that such technologies can contribute to formation of transitory collective identities, but not durable collective identities required for social movement development. Returning back to the Actor-Network Theory framework it is important to question

\footnotetext{
22 McAdam, Political Process and the Development of Black Insurgency, 1930-1970.

${ }^{23}$ Ganz, "Public Narrative, Collective Action, and Power."

${ }^{24}$ McAdam, McCarthy, and Zald, Comparative Perspectives on Social Movements.

${ }^{25}$ Gamson, "Arab Spring, Israeli Summer, and the Process of Cognitive Liberation."

${ }^{26}$ McAdam, McCarthy, and Zald, Comparative Perspectives on Social Movements, 5.

27 Myers, "Communication Technology and Social Movements."

${ }^{28}$ Majid Tavakoli is a student leader and human rights activist. He was arrested in 2009 during protests in Tehran and state media showed images of him in a headscarf to discredit him by insinuating that he was trying to escape disguised as a woman. In matter of hours, social media stormed with photos of thousands of men wearing hijab to show their solidarity with Majid Tavakoli and questioning gender issues ("Iranian Men Don Hijabs in Protest."). This was an example of the formation of a transitory collective identity that initiated quickly and expanded very fast, although did not last for a long time.
} 
whether such mobile but non-durable technologies can challenge the existing networks of power in the longterm.

\section{The Political Use of Technology}

Early assertions relating to the use of social media throughout the Arab Spring uprisings claimed that use of the tools allowed organizers to reach a larger number of individuals more quickly than earlier forms of communication. By doing so, the people were able to organize and raise their voices against the power status quo. While elements of this may be true there is another side of social media and technology use that needs to be considered. As discussed earlier in this article, technologies operate within a socio-technical framework. If we were to analyze one aspect of their implementation without mention of the other we would only be providing part of the story.

Social media tools also provide tools for government engagement. In the case of Iran, there is little chance of widespread use of a social media tool that can't be monitored by the government. While people are oppressed under strict rules, lack of social freedom and a repressive environment, they can still find refuge in their social online niches. With this in mind we have asked if Marx's critique of religion can be applied to social media use. "Religious suffering is, at one and the same time, the expression of real suffering and a protest against real suffering. Religion is the sigh of the oppressed creature, the heart of a heartless world, and the soul of soulless conditions. It is the opium of the people ${ }^{29}$. It is important to note that religion in itself is not the target of Marx's condemnation but is considered an outlet for suffering. In this way one could consider social media, specifically Facebook, as both the safety valve that relieves the pressure of social restriction and as one of the tools that helps ensure that social unrest is allowed just enough freedom to keep it suppressed.

\section{Conclusion}

The present study suggests that to better understand the relationship between social media and social change, we have to use a relational sociology perspective such as Actor-Network Theory (ANT). From this theoretical stance social order is considered as the effect of a heterogeneous network of social and technical phenomena. We suggested utilizing the concepts of "durability" and "mobility" in studying social media borrowed form ANT vocabulary. The evidence from literature suggests that social media technologies are very mobile; however, we believe that mobility of such technologies shadowed the importance of inquiries about the durability social media technologies. The preliminary findings of this exploratory study of Iranian Facebook users suggests that online social networking technologies and social media created very complex relationships within the social context that might not be well understood. We have discussed that time is an important factor to evaluate the durability of such technologies in favor of social change. However, in the mid-stage of a social movement development, we have noticed that social media might have counter-effects by working as a pressure valve to relieve some of the frustration built up through various societally imposed disappointments and to vent the steam that may drive social change. These issues need more in depth study to better understand the efficacy of social media for revolutionary change in the future.

Due to the complex nature of the relationship between social and technical phenomena, this study suggests that the role new ICTs play in social movements and social change is not linear and constant through time. The impact of new ICTS might be different considering different stages in a social movement timeline. Therefore, we encourage a framing of studies which contemplate the relationship between new ICTs and social change in three different stages of a social movement timeline as early stage (emergence of movements), mid-stage (development or decline of movements), and late-stage (the movement's continuation, survival or disappearance through time). It is important to critically analyze the use of social media, particularly in contemporary instances such as the Arab Spring, flash mob activity, and rioting. There is more to the situation

${ }^{29}$ Marx, Critique of Hegel's "Philosophy Of Right,"131. 
than the technical capability afforded through use of technology. It is still important to consider the political and historical contexts of the action.

\section{References}

Benford, Robert D., and David A. Snow. "Framing Processes and Social Movements: An Overview and Assessment." Annual Review of Sociology 26 (January 1, 2000): 611-639.

Bennett, W. Lance, and Alexandra Segerberg. "Digital Media and the Personalization of Collective Action." Information, Communication \& Society 14, no. 6 (2011): 770-799.

Bennett, W. Lance. "The Personalization of Politics Political Identity, Social Media, and Changing Patterns of Participation." The ANNALS of the American Academy of Political and Social Science 644, no. 1 (n.d.): 20-39.

Callon, Michel. "Some Elements of a Sociology of Translation: Domestication of the Scallops and the Fishermen of St Brieuc Bay. "In Power, Action, and Belief: A New Sociology of Knowledge?, edited by John E Law, 196-233. Sociological Review Monograph 32. London; Boston: Routledge \& Kegan Paul, 1986.

van de Donk, Wim, Brian D. Loader, Paul G. Nixon, and Dieter Rucht, eds. Cyberprotest: New Media, Citizens, and Social Movements. London; New York: Routledge, 2004.

Gamson, William A. "Arab Spring, Israeli Summer, and the Process of Cognitive Liberation." Swiss Political Science Review 17, no. 4 (2011): 463-468.

Ganz, Marshall. "Public Narrative, Collective Action, and Power." In Accountability Through Public Opinion: From Inertia to Public Action, edited by Sina Odugbemi and Taeku Lee, 273-289. World Bank Publications, 2010.

Garrett, R. Kelly. "Protest in an Information Society: a Review of Literature on Social Movements and New ICTs. "Information, Communication \& Society 9, no. 2 (April 2006): 202-224.

"Iranian Men Don Hijabs in Protest." BBC, December 12, 2009, sec. Middle East. http://news.bbc.co.uk/2/hi/middle_east/8409778.stm.

Latour, Bruno. Reassembling the Social: An Introduction to Actor-Network-Theory. Clarendon Lectures in Management Studies. Oxford; New York: Oxford University Press, 2005.

Law, John E. "Notes on the Theory of the Actor Network: Ordering, Strategy and Heterogeneity. "Center for Science Studies, Lancaster University, 1992. www.lancs.ac.uk/fass/sociology/papers/law-notes-onant.pdf.

- . "On the Methods of Long-distance Control: Vessels, Navigation and the Portuguese Route to India." In Power, Action, and Belief: A New Sociology of Knowledge?, edited by John E Law, 234-263. Sociological Review Monograph 32. London; Boston: Routledge \& Kegan Paul, 1986.

Lindlof, Thomas R, and Bryan C Taylor. Qualitative Communication Research Methods. 2nd ed. Thousand Oaks, Calif: Sage Publications, 2002.

Marx, Karl. Critique of Hegel's "Philosophy Of Right." Edited by Joseph O'Malley. CUP Archive, 1977.

McAdam, Doug, John D. McCarthy, and Mayer Zald, eds. Comparative Perspectives on Social Movements: Political Opportunities, Mobilizing Structures, and Cultural Framings. Cambridge Studies in Comparative Politics. Cambridge; New York: Cambridge University Press, 1996.

McAdam, Doug. Political Process and the Development of Black Insurgency, 1930-1970. Chicago: University of Chicago Press, 1982.

Meier, Patrick. "Do 'liberation Technologies' Change the Balance of Power Between Repressive States and Civil Society?" PhD, Tuft University, 2011.

Myers, Daniel J. "Communication Technology and Social Movements: Contributions of Computer Networks to Activism." Social Science Computer Review 12, no. 2 (July 1, 1994): 250-260.

Orlikowski, Wanda J. "Sociomaterial Practices: Exploring Technology at Work." Organization Studies 28, no. 9 (2007): $1435-1448$.

Patton, Michael Quinn. Qualitative Research and Evaluation Methods. 3rd ed. Thousand Oaks, Calif: Sage Publications, 2002. 
Snow, David A., E. Rochford, S. Worden, and Robert D. Benford. "Frame Alignment Processes, Micromobilization, and Movement Participation." American Sociological Review 51, no. 4 (August 1986): 464.

Wojcieszak, Magdalena, Briar Smith, and Mahmood Enayat. Finding a Way: How Iranians Reach for News and Information. The Iran Media Program's 2011-2012 Report on Media Consumption in Iran. Philadelphia: Iran Media Program, 2012. http://iranmediaresearch.org/en/research/pdffile/990. 